\title{
Developmental Changes in Hippocampal Associative Coding
}

\author{
Mary E. Goldsberry, Jangjin Kim, and John H. Freeman \\ Department of Psychology, University of Iowa, Iowa City, Iowa 52242
}

Behavioral analyses of the ontogeny of memory have shown that hippocampus-dependent learning emerges relatively late in postnatal development compared with simple associative learning. Maturation of hippocampal mnemonic mechanisms has been hypothesized to underlie the development of the later emerging learning processes. However, the role of hippocampal maturation in learning has not been examined directly. The goal of the present study was to examine developmental changes in hippocampal neuronal coding during acquisition of a hippocampus-dependent learning task. We recorded activity from CA1 pyramidal cells in rat pups while they were trained on trace eyeblink conditioning. Trace eyeblink conditioning is a Pavlovian conditioning task that involves the association of a conditioned stimulus (CS) with an unconditioned stimulus over a stimulus-free trace interval. The inclusion of the trace interval is what makes the task hippocampus dependent. In the present study, rats were trained at 21-23, 24-26, and 31-33 d of age. Previous research from our laboratory and others shows that trace conditioning begins to emerge during the third postnatal week. The results indicate that hippocampal neurons show a substantial increase in responsiveness to task-relevant events during development. Moreover, there is an age-related increase in the proportion of neurons that respond to a combination of trial events (e.g., CS and trace). Our findings indicate that the developmental emergence of hippocampally mediated learning is related to increases in the strength and complexity of CA1 associative coding.

Key words: CA1; development; eyeblink conditioning; hippocampus; ontogeny; trace conditioning

\section{Introduction}

Developmental studies of learning and memory indicate that hippocampus-dependent memory develops after hippocampusindependent memory in altricial mammalian species such as humans, monkeys, and rats (Stanton, 2000; Stanton et al., 2009). Learning that is independent of hippocampal function tends to emerge much earlier in development, in some cases even prenatally (Smotherman, 1982). However, due to the relatively late maturation of forebrain structures such as the hippocampus, other types of learning do not begin to emerge until much later in development (Ivkovich and Stanton, 2001). Several approaches have been used to examine the development of learning, including behavioral analyses of hippocampus-dependent tasks such as spatial learning. Spatial learning emerges relatively late in altricial species and parallels some aspects of hippocampal anatomical development (Rudy and Paylor, 1988; Green and Stanton, 1989; Freeman and Stanton, 1991). Rudy and Paylor (1988) found that although postnatal day 22 (P22) rat pups successfully learn the water maze place-learning task, P19 pups are unable to. One possible explanation for the delayed development of place learning could be that it is limited by the development of hippocampal function. Recent work characterizing the

\footnotetext{
Received July 29, 2014; revised Jan. 26, 2015; accepted Feb. 3, 2015.

Author contributions: M.E.G. and J.H.F. designed research; M.E.G. performed research; M.E.G. and J.K. analyzed data; M.E.G. and J.H.F. wrote the paper.

This work was supported by National Institutes of Health (Grant NS038890 to J.H.F.). We thank Magdalyn Elkin and $\mathrm{Ka} \mathrm{Ng}$ for technical assistance.

The authors declare no competing financial interests.

Correspondence should be addressed to John H. Freeman, Department of Psychology, E11 Seashore Hall, University of lowa, lowa City, IA 52242. E-mail: john-freeman@uiowa.edu.

DOI:10.1523/JNEUROSCI.3145-14.2015

Copyright $\odot 2015$ the authors $\quad 0270-6474 / 15 / 354238-10 \$ 15.00 / 0$
}

development of place fields in the hippocampus has indirectly supported this hypothesis by demonstrating that the development of place fields occurs between the ages of P16 and P28 (Langston et al., 2010; Wills et al., 2010). However, these studies did not directly examine the relationship between hippocampal physiological development and the ontogeny of memory. Moreover, the behavioral development of complex memory processes such as spatial navigation can be difficult to compare across ages due to the concurrent development of sensory processing and motor control.

One possible solution to these limitations is to employ a learning task that is less affected by motor and sensory development such as eyeblink conditioning (Stanton et al., 1992). The primary goal of the present study was to examine the relationship between hippocampal physiological development and the ontogeny of a hippocampus-dependent task, trace eyeblink conditioning. In trace eyeblink conditioning, a conditioned stimulus (CS, e.g., a tone) is followed by an unconditioned stimulus (US) that elicits a reflexive blink. The CS and US are temporally separated by a brief stimulus-free "trace" interval. The inclusion of this trace interval makes the task hippocampus dependent (Solomon et al., 1986; Moyer, Deyo, and Disterhoft, 1990; Clark et al., 2002). Adult hippocampal CA1 pyramidal cells respond to the events within the trace conditioning trials including the CS, trace interval, and the US (McEchron and Disterhoft, 1997; Weible et al., 2006; Green and Arenos, 2007). The late emergence of trace conditioning parallels the developmental trajectory of spatial learning and is likewise believed to be due to delayed development of the hippocampus and other forebrain structures (Ivkovich et al., 2000). If the developmental trajectory of this learning task is indeed due to the late development of the hippocampus we would anticipate 
Table 1. Count and percentage of neurons in categories of responsiveness

\begin{tabular}{lcccc}
\hline & P21-P23 & P24-P26 & P31-P33 & All ages \\
\hline Paired training & & & & \\
Nonresponsive & $152(48.9 \%)$ & $188(45.2 \%)$ & $282(48.4 \%)$ & $622(47.5 \%)$ \\
CS-responsive & $2(0.6 \%)$ & $1(0.2 \%)$ & $11(1.9 \%)$ & $14(1.1 \%)$ \\
Trace-responsive & $6(1.9 \%)$ & $21(5 \%)$ & $8(1.4 \%)$ & $35(2.7 \%)$ \\
US-responsive & $86(27.7 \%)$ & $89(21.4 \%)$ & $109(18.7 \%)$ & $284(21.7 \%)$ \\
CS- and trace-responsive & $8(2.6 \%)$ & $2(0.5 \%)$ & $7(1.2 \%)$ & $17(1.3 \%)$ \\
CS- and US-responsive & $3(1.0 \%)$ & $7(1.7 \%)$ & $27(4.6 \%)$ & $37(2.8 \%)$ \\
Trace- and US-responsive & $14(4.5 \%)$ & $59(14.2 \%)$ & $47(8.1 \%)$ & $120(9.2 \%)$ \\
CS-, trace-, and US-responsive & $40(12.9 \%)$ & $49(11.8 \%)$ & $92(15.9 \%)$ & $181(13.8 \%)$ \\
Grand total & $311(100 \%)$ & $416(100 \%)$ & $583(100 \%)$ & $1310(100 \%)$ \\
Combination neurons & $65(20.9 \%)$ & $117(28.1 \%)$ & $173(29.7 \%)$ & $355(27.1 \%)$ \\
Unpaired training & & & & \\
Nonresponsive & $77(45.6 \%)$ & $132(66.3 \%)$ & $86(64.2 \%)$ & $295(58.8 \%)$ \\
CS-responsive & $7(4.1 \%)$ & $10(5.0 \%)$ & $8(6.0 \%)$ & $25(5.0 \%)$ \\
US-responsive & $80(47.3 \%)$ & $53(26.6 \%)$ & $30(22.4 \%)$ & $163(32.5 \%)$ \\
CS- and US-responsive & $5(3.0 \%)$ & $4(2.0 \%)$ & $10(7.5 \%)$ & $19(3.8 \%)$ \\
Grand total & $169(100 \%)$ & $199(100 \%)$ & $134(100 \%)$ & $502(100 \%)$ \\
\hline
\end{tabular}

During paired training, CA1 neurons were categorized in one of eight categories according to the trial events to which they were responsive. During unpaired training, neurons were categorized in one of four categories. The number and percentage (in parentheses) is noted for each category and age group. Based on these values, the number (and percentage) of units that responded to more than one trial event was calculated and labeled as "combination neurons."

age- and learning-related changes in the responsiveness of hippocampal neurons.

\section{Materials and Methods}

Subjects. Subjects were 15 Long-Evans rat pups ( 7 females and 8 males), all from different litters. For paired training ( 6 sessions), there were 3 pups used in each age group. For unpaired training (also 6 sessions per animal), there were 3 pups in the oldest age group, 2 pups in the middle age group, and 1 pup in the youngest age group. For neuron counts per group, please see Table 1. All pups were born and reared in the Spence Laboratories of Psychology animal colony at the University of Iowa. The colony was maintained on a 12/12 h light/dark cycle, with light onset at 7:00 A.M. All procedures were approved by the University of Iowa Institutional Animal Care and Use Committee.

Surgery. Detailed surgical methods have been described previously (Ng and Freeman, 2012). We implanted rat pups with microdrives for neuronal recording with multiple tetrodes on P19, P22, and P29, $2 \mathrm{~d}$ before training. Pups were anesthetized using $1.5-3 \%$ isoflurane gas. During surgery, rats were fitted with a microdrive for neuronal recording, differential EMG electrodes to record blink activity, and a bipolar stimulating electrode for US delivery.

For microdrive implantation, a small hole was drilled in the skull directly above the right dorsal hippocampus (AP, $-4.0 \mathrm{~mm}$; ML, -2.5 $\mathrm{mm}$ ). The microdrive was lowered until the tetrodes touched the brain surface. Any additional space between the drive and the skull was filled with a low-viscosity silicone gel (Kwik-Sil; World Precision Instruments). The microdrive was then grounded with a stainless steel screw fixed to the skull. Immediately after implantation, the tetrodes were lowered $\sim 0.6 \mathrm{~mm}$ into the brain.

To record differential EMG activity from the eyelid, two stainless steel electrodes were threaded through the left upper orbicularis oculi muscle and a ground wire was attached to the skull with a screw. The bipolar stimulating electrode for US delivery was placed subdermally immediately caudal to the left eye.

On the day after surgery, spike activity was monitored as the recording tetrodes were lowered into the CA1 layer $(\sim \mathrm{DV},-2.1 \mathrm{~mm})$ and the reference tetrode was lowered into the cortex dorsal to the hippocampus $(\sim \mathrm{DV},-0.9)$.

Spike data acquisition. Spike data acquisition has been described previously in detail (Ng and Freeman, 2012). Pups were surgically implanted with either an 8- or 16-channel microdrive array for either 2 or 4 recording tetrodes, respectively. Each drive had a separate, independently mov- ing reference channel tetrode. Before implantation, each tetrode was gold-plated until the tetrode impedance was $\sim 350 \mathrm{k} \Omega$.

During data collection and tetrode lowering, the microdrive was connected to a spike acquisition system (Neuralynx). The spike signal was then amplified at a gain of 10,000-25,000 and band-pass filtered between 0.6 and $6.0 \mathrm{kHz}$. Signals were digitized and stored at $32 \mathrm{kHz}$ (Cheetah; Neuralynx).

Conditioning apparatus. The conditioning apparatus has been described previously in detail ( $\mathrm{Ng}$ and Freeman, 2012). Rat pups were trained within a conditioning chamber that was contained within a sound-attenuation chamber. Lightweight cables with connectors for both the recording EMG and the bipolar US electrode were attached to a commutator above the conditioning chamber and threaded through a hole in the ceiling of the chamber. Computer software controlled the delivery of both CS and US while simultaneously recording differential eyelid EMG activity (sampling rate $=250 \mathrm{~Hz}$ ). EMG activity was amplified $(\times 2000)$, filtered $(500-5000 \mathrm{~Hz})$, and integrated $(20 \mathrm{~ms}$ time constant).

Conditioning procedures. To parse out nonassociative responding to the CS from learning, pups were given either paired or unpaired presentations of the CS and US. Pups in the paired group received 100 trials per session of trace EBC with a $250 \mathrm{~ms}(2 \mathrm{kHz})$ tone CS, a $500 \mathrm{~ms}$ trace interval, and a $25 \mathrm{~ms}$ periorbital stimulation US (2-3 mA; see Fig. $1 B)$. In adult animals, this training paradigm results in a learned association between the CS and US. Each paired session was divided into 10 blocks of 10 trials. The first nine trials of the block were paired CS-US presentations and the tenth trial of each block was a probe trial containing only the tone CS. The probe trials were used to evaluate conditioned responding $(\mathrm{CR})$ in the absence of the unconditioned response (Gormezano et al., 1983). Paired trials were separated by a variable intertrial interval that averaged $30 \mathrm{~s}$. Learning was demonstrated by the presence of a CR after $\mathrm{CS}$ onset but before US onset on a given trial. The CR threshold was $0.4 \mathrm{~V}$ above the amplified and integrated baseline EMG activity. Pups in the unpaired group received 200 trials per session of either the CS or the US. In adult animals, unpaired training does not result in a learned association because the CS and US are presented separately. Unpaired trials were separated by a variable intertrial interval that averaged $15 \mathrm{~s}$. Any response that occurred during the first $80 \mathrm{~ms}$ of the CS was considered a startle response and was omitted from future analyses.

Neuronal recording analyses. Offline neuron separation was initially performed automatically with KlustaKwik (Kadir et al., 2014). Separated neurons were then manually inspected and refined using MClust-3.5 (Redish et al., 2010). Neurons were classified as pyramidal cells if they: (1) showed a bursting pattern of activity as demonstrated by a peak in the autocorrelogram at 3-8 $\mathrm{ms}$, (2) had a baseline (500 ms sample duration before CS onset) firing rate of $<10.5$ spikes/s, and (3) had at least 300 spikes during the training session.

Neuronal activity was then analyzed in relation to trial event responsivity using NeuroExplorer. First, neurons were classified according to the trial event(s) they responded to (CS, trace interval, US). To accomplish this, the trial was divided into nine $125 \mathrm{~ms}$ intervals. The nine time intervals included baseline (125 ms), CS (250 ms), trace (500 ms), and US periods $(250 \mathrm{~ms})$. Firing rate for each neuron was normalized to the pre-CS baseline using $z$-score values in NeuroExplorer. Intervals that had values exceeding the preestablished $99 \%$ confidence limits based on the Poisson distribution (two-tailed, $\alpha<0.05$ ) were considered to be statistically significant from the baseline firing rate, thus showing either excitatory or inhibitory responses to trial events. Based on which intervals were different from baseline, neurons were classified as unresponsive, CS-responsive, trace-responsive, US-responsive, or a combination thereof. Therefore, categories were overlapping and combination units could be considered as belonging to more than one category. For example, a unit that showed increased activity during both the CS and the US periods would be categorized as a CS-responsive unit and a USresponsive unit (see Fig. 2). The proportion of neurons that fell into each response category was compared across age groups and sessions with $\chi^{2}$ analyses.

The magnitude of the neuronal response was also examined. Peristimulus-time histograms of neuronal activity were generated with 

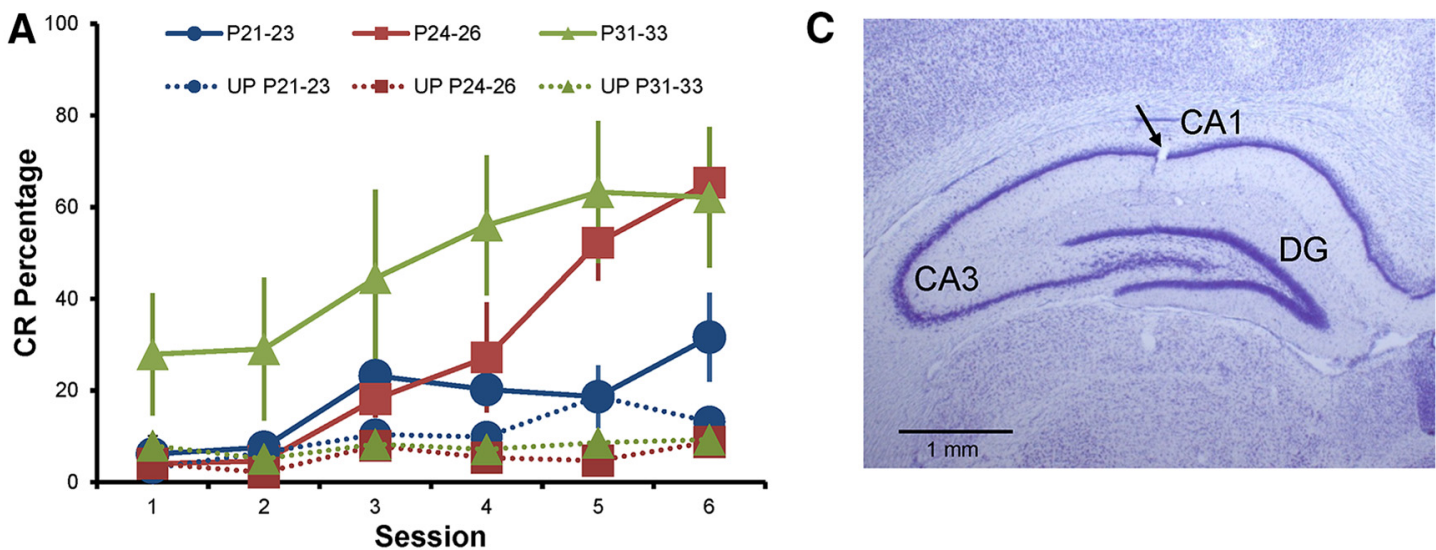

B

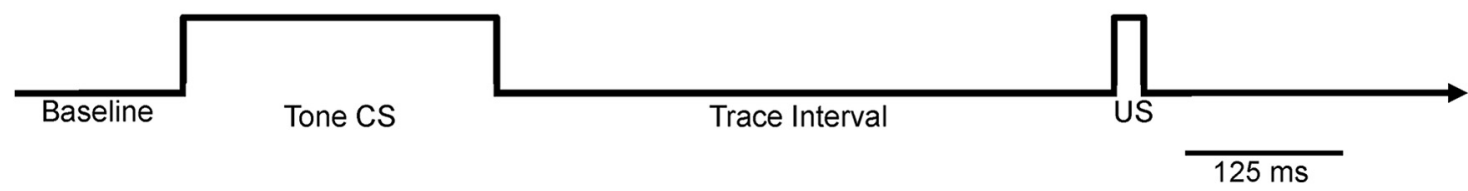

Figure 1. Hippocampus-dependent learning increases as a function of age. $A$, Mean $( \pm S E) C R$ percentage in rat pups given trace eyeblink conditioning on P21-P23 (paired group, $n=3$; unpaired group, $n=1$ ), P24-P26 (paired group, $n=3$; unpaired group, $n=2$ ), or P31-P33 (paired group, $n=3$; unpaired group, $n=3$ ). There was an increase in (R percentage as a function of age in the pups given paired training, but not in the pups given unpaired training. $\boldsymbol{B}$, The paired trace conditioning procedure involved a $250 \mathrm{~ms}$ tone $C S$, a stimulus-free $500 \mathrm{~ms}$ trace interval, and 25 ms periorbital stimulation US. C, Representative Nissl-stained coronal brain section with tetrode placement in CA1 layer of hippocampus. The tetrode-marking lesion is indicated by arrow.

$12.5 \mathrm{~ms}$ bins and normalized as follows: normalized bin $=($ bin mean $125 \mathrm{~ms}$ baseline mean)/SD of $125 \mathrm{~ms}$ baseline). The normalized bin values of responsive neurons were then compared across age and CR/ no-CR trials with a repeated-measures ANOVA and the Tukey HSD post hoc test to examine age-related differences in the magnitude of neuronal responding during the trial.

Histology. Histological methods have been described previously in detail (Ng and Freeman, 2012). Tetrode placement was determined by creating small electrolytic lesions after the last session of training. Brains were placed in a $30 \%$ sucrose-formalin solution upon removal, sectioned at $50 \mu \mathrm{m}$, mounted on slides, and stained with thionin. Histology was then examined with a light microscope to determine tetrode placement. Only placements confirmed to be in the CA1 layer of the hippocampus were included in the analysis.

\section{Results}

\section{Behavioral data}

Behavioral analyses of learning, as demonstrated by conditioned responding across age and training type, revealed that there were significant differences between groups (Fig. 1A). When pups received paired training, there was an age-related increase in learning, with older pups learning the association better than younger pups. However, there were no significant differences between age groups when pups received unpaired training. These observations were confirmed with a repeated-measures ANOVA examining differences in the percentage of CRs across sessions (sessions 1-6), training condition (paired vs unpaired), and age (P21-P23, P24-P26, or P31-P33), which found a session $\times$ training condition $X$ age interaction $\left(F_{(10,45)}=2.654, p=0.012\right.$; Fig. 1A). This interaction was further examined with Tukey HSD post hoc tests. During paired training, the P31-P33 age group had a significantly greater $\mathrm{CR}$ percentage on sessions $1-6$ than did the P21-P23 group $(p<0.01)$. The P31-P33 age group also had a significantly higher CR percentage on sessions 1-4 compared with the P24-P26 age group ( $p<0.01)$. Finally, the two youngest age groups differed from each other on sessions $5-6(p<0.01)$. For unpaired training, there were no significant differences in the percentage of CRs across age.

\section{Neuronal responsiveness}

Recorded pyramidal neurons from the CA1 field of the hippocampus were categorized (Fig. 2) according to their firing rates as either responsive or unresponsive to trial events $(n=1812)$. Responsiveness was further categorized as either excitatory (showing increases in activity) or inhibitory (showing decreases in activity). The proportion of neurons that showed inhibitory responses was extremely low and was therefore excluded from further statistical analyses. The proportion of neurons that showed either excitatory or no response were then compared across categories using $\chi^{2}$ analyses (Table 1). The proportion of excitatory responsive neurons was greater when pups were given paired training than unpaired training $\left[X^{2}(1, N=1812)=18.49\right.$, $p=0.0001$; Fig. 3$]$. These differences in neuronal responsiveness across paired and unpaired training indicate that the associative nature of the CS and US during paired training leads to an increase in neuronal recruitment.

Within the paired training group, there were no differences across age for the proportion of responsive versus unresponsive neurons $\left[X^{2}(2, N=1310)=1.30, p>0.05\right]$. However, this analysis only examined overall responsiveness and did not take into account responsiveness to individual trial events (e.g., the US). When trial components were broken down into CS, trace, and US components, several age-related changes were found.

\section{Proportion of responsive neurons during paired training}

When CS responsivity was examined, an age-related increase in the proportion of neurons that responded to the CS was observed $\left[X^{2}(2, N=1310)=14.71, p=0.0006\right.$; Fig. $\left.3 A\right]$. However, the proportion of neurons that were responsive to the CS alone, as opposed to those responsive to the CS in combination with other trial events, was too low to compare statistically between age groups. During paired training, there were no significant differences across age in the proportion of neurons that showed responses to the US $\left[X^{2}(2, N=1310)=0.71, p=0.70\right.$; this category included combination neurons that were also responsive to the CS and trace interval; Fig. $3 B$ ]. However, when exam- 

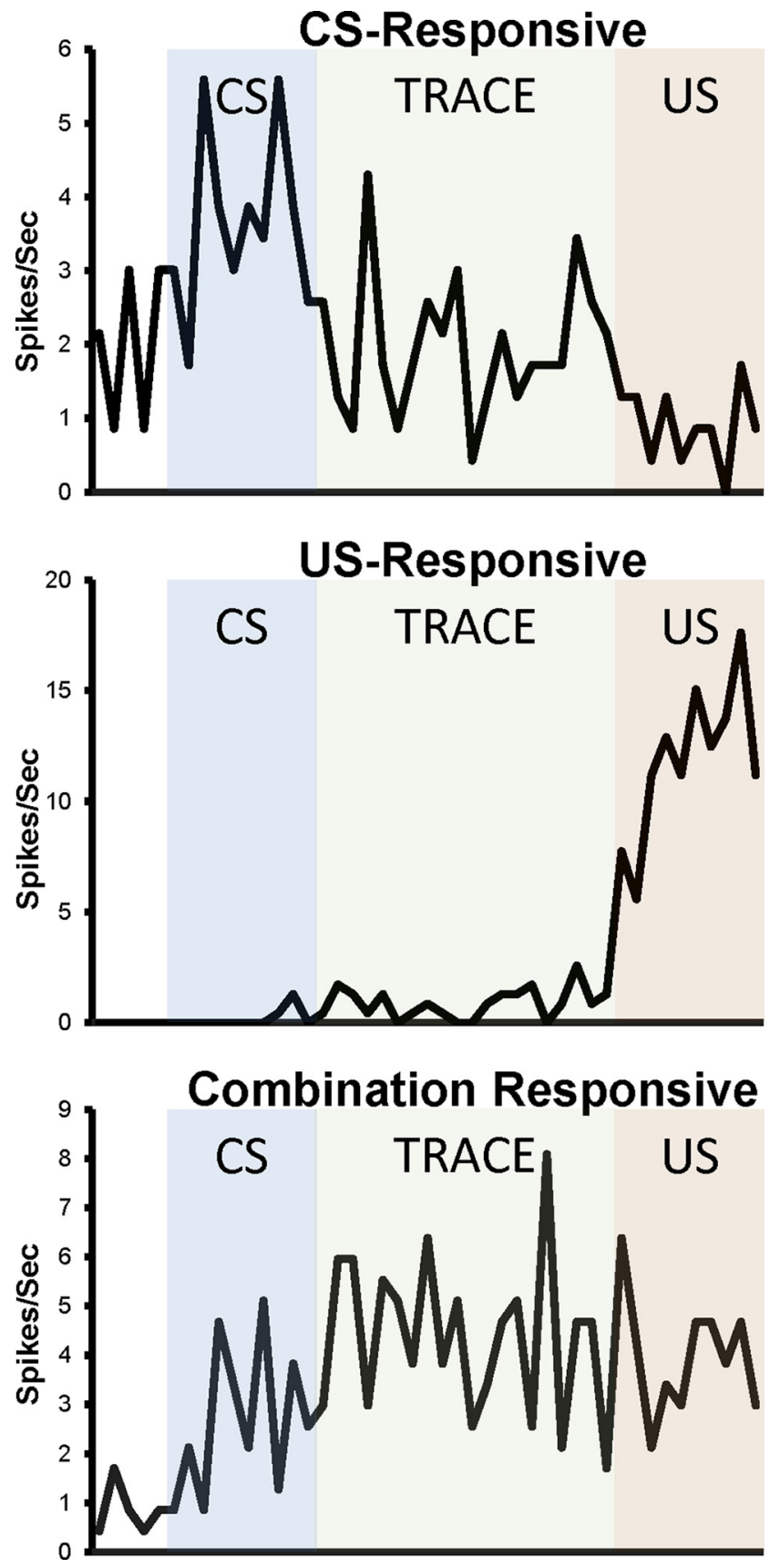

Figure 2. Example CA1 pyramidal cell firing rate profiles during trial presentation. All figures include pre-CS baseline (125 ms), CS ( $250 \mathrm{~ms})$, trace $(500 \mathrm{~ms})$, and US ( $250 \mathrm{~ms})$ intervals.Z-score analyses were used to categorize neurons according to the responsiveness to trial events $(p<$ 0.01 ). The proportion of neurons in each category was compared across training conditions and age groups.

ining the proportion of neurons that showed increases in activity uniquely during the US (therefore not US combination neurons), a significant effect of age was found, with the proportion of USonly responsive neurons decreasing with age $\left[X^{2}(2, N=1310)=\right.$ 9.61, $p=0.008$; Fig. 3C]. Therefore, although all age groups showed similar levels of US responsivity, older pups tended to have neurons that responded to the US in combination with other trial events, whereas younger pups were more likely to have neurons that responded only to the US. In younger animals, the increased proportion of neurons that were responsive to the US alone could be interpreted as a neuronal representation of sur- prise to the US presentation due to weaker associative prediction (Rescorla and Wagner, 1972). A second interpretation of these results is that the increased activity during the US is learning related and serves as a precursor to the overt learned response (Berger et al., 1976).

There was also an age-related difference in the proportion of neurons that showed responding to a combination of trial events $\left[X^{2}(2, N=1310)=6.64, p=0.036\right.$; Fig. $\left.3 D\right]$. Younger animals had a lower proportion of cells that responded to a combination of trial events when compared with older animals. Therefore, the older a pup is, the more likely its hippocampal neurons are to respond to a combination of trial events (Fig. 3).

Learning-related changes in the proportion of responsive neurons during paired training

To investigate how learning affected neuronal activity, the proportion of neurons that showed changes in responsiveness between CR and no-CR trials were compared across age and sessions. Only neurons that showed responsiveness to trial events were included in the analysis. Depending on whether the responsiveness category was same or different between CR and no-CR trials, 2 different categorical values (e.g., 1 for same and 0 for different) were assigned to each neuron. These values were compared across sessions as well as across the age group with a Pearson's $\chi^{2}$ test. Note that we excluded sessions in which the CR percentage was $<5 \%$ or $>95 \%$ to have minimum numbers of samples in both the CR and no-CR conditions.

The proportion of neurons that responded differentially during $\mathrm{CR}$ and no-CR trials did not differ significantly when compared across age groups $\left[X^{2}(2, N=648)=1.210, p=0.546\right]$. Therefore, although all three age groups had a large number of neurons that differed in responsiveness between $\mathrm{CR}$ and no-CR trials, there were no significant age-related differences (Fig. 4A). When broken down by session as well as age group, betweengroup differences in responding were found during session 2 $\left[X^{2}(2, N=122)=7.098, p=0.029\right]$. However, during the other sessions, the proportions were not statistically different across age groups $\left[X^{2}(2, N \geq 84)<2.297, p>0.317\right.$; Fig. $\left.4 B\right]$. Last, the proportion of units that showed differential responses between $\mathrm{CR}$ and no-CR trials was examined across sessions separately for each age group. In the youngest two age groups, the proportion of neurons that showed differential responsiveness was not statistically different across sessions $\left[X^{2}(2, N \geq 140)<7.268, p>0.201\right]$. In the P31-P33 age group, however, the proportion of neurons that responded differentially to CR and no-CR trials significantly decreased across sessions $\left[X^{2}(5, N=294)=16.755, p=0.005\right]$.

\section{Proportion of responsive neurons during unpaired training}

In contrast to paired training, during unpaired training, the proportion of responsive neurons differed significantly across age, with an age-related decrease in responsivity $\left[X^{2}(2, N=502)=\right.$ 22.84, $p=0.00001]$. When examining trial events during unpaired training, there was a difference in US responsiveness across age (Fig. $3 B$ ). The youngest age group had a greater proportion of responsive neurons compared with the oldest two age groups $\left[X^{2}(2, N=502)=21.73, p=0.000003\right]$. This increased proportion of US-responsive neurons was primarily due to the extremely high proportion of US-responsive neurons during the first three sessions of P21-P23 unpaired training (session 1: 88\%, session 2: $58 \%$, session 3: $64 \%$ ). Indeed, there was a significant decrease in the proportion of US-responsive neurons as unpaired training continued $\left[X^{2}(5, N=169)=39.21, p=0.0000002\right]$. By the end of training, the P21-P23 group neurons showed a similar level of US responsiveness to that seen in the older groups. 
A CS-Responsive Neurons

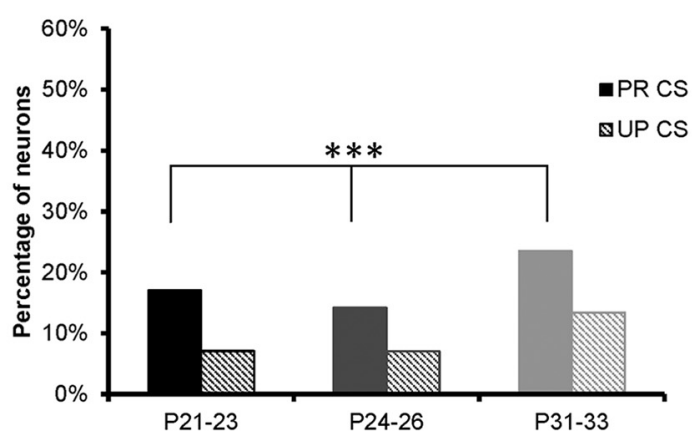

B US-Responsive Neurons

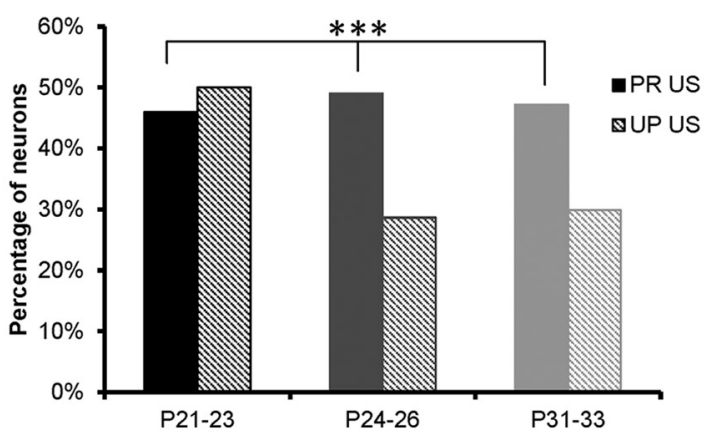

\section{US-Only Responsive Neurons}

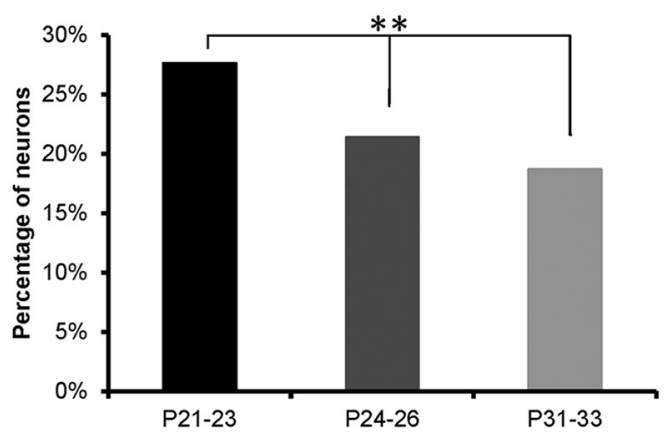

D Combination Neurons

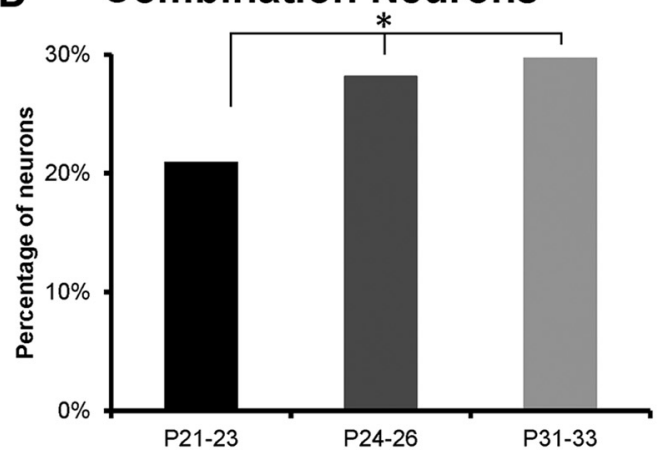

Figure 3. Hippocampal neurons respond differentially to trial events. $A$, Age-related difference in the proportion of cells that respond to the tone CS during paired but not unpaired training (this category includes neurons that were also responsive to other trial events, i.e., $\mathrm{CS}$ neurons that were also responsive to the trace interval). The difference in activity between paired and unpaired training is an index of associative activation. $\boldsymbol{B}$, Age-related difference in the proportion of neurons that responded to the US during unpaired but not paired training (this category includes neurons that were also responsive to other trial events, i.e., US neurons that were also responsive during the trace interval). The drop in US-related activity during unpaired training with age is related to learning that the CS does not predict the US. C, Proportion of US-only responsive neurons decreased with age, which reflects an age-related increase in the proportion of neurons that respond to the US in combination with other learning-related events. $\boldsymbol{D}$, An age-related increase in the percentage of neurons that respond to a combination of trial events (CS, trace interval, and US) was also found. These findings indicate that there was a developmental increase in the percentage of neurons that showed complex coding of learning-related events.
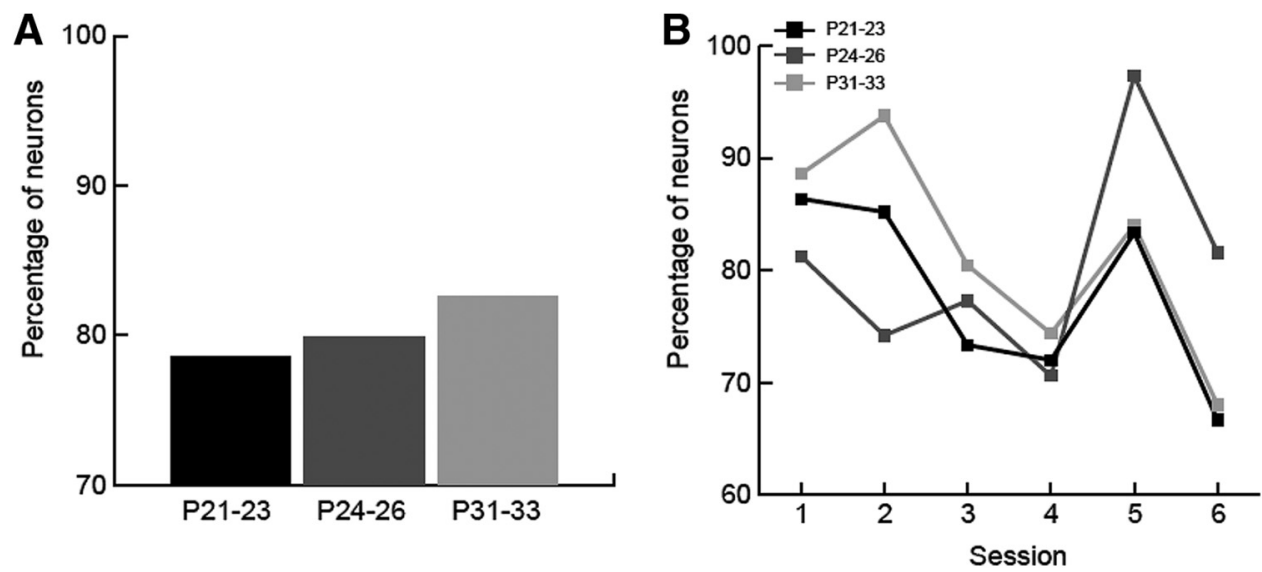

Figure 4. Learning-related changes in neuronal responsiveness. $A$, The percentage of cells that responded differently during $C R$ and no-CR trials was similar across age group (total number of significantly responding neurons used as denominator). $\boldsymbol{B}$, When broken down by session, there were age-related differences in the proportion of neurons that responded differently during $(R$ versus No-CR trials (total number of significantly responding neurons used as denominator). Although the younger two age groups tended to show similar proportions of differently responding neurons throughout training, the oldest age group had a steep decrease in the proportion of neurons that responded differently.

Changes in neuronal responsiveness across sessions in all age groups

Differences in neuronal responsiveness across sessions were found. There was a significant decrease in the proportion of responsive neurons across sessions during both paired $\left[X^{2}(5, N=\right.$ $1310)=26.82, p=0.00006]$ and unpaired $\left[X^{2}(5, N=502)=\right.$ $24.81, p=0.0002$ training; Fig. 5]. When neuronal responsiveness during unpaired sessions was further examined, $\chi^{2}$ analyses showed that the significant decrease in responding across sessions was most likely due to the US-responsive neurons. The proportion of US-responsive $\left[X^{2}(5, N=502)=21.57, p=0.0006\right]$, but not CS-responsive $\left[X^{2}(5, N=502)=10.35, p=0.066\right]$ neurons significantly decreased across training sessions. When neuronal responsiveness across sessions was examined during paired training, $\chi^{2}$ analyses revealed that the proportion of both CS-responsive $\left[X^{2}(5, N=1310)=24.25, p=0.0002\right]$ and 


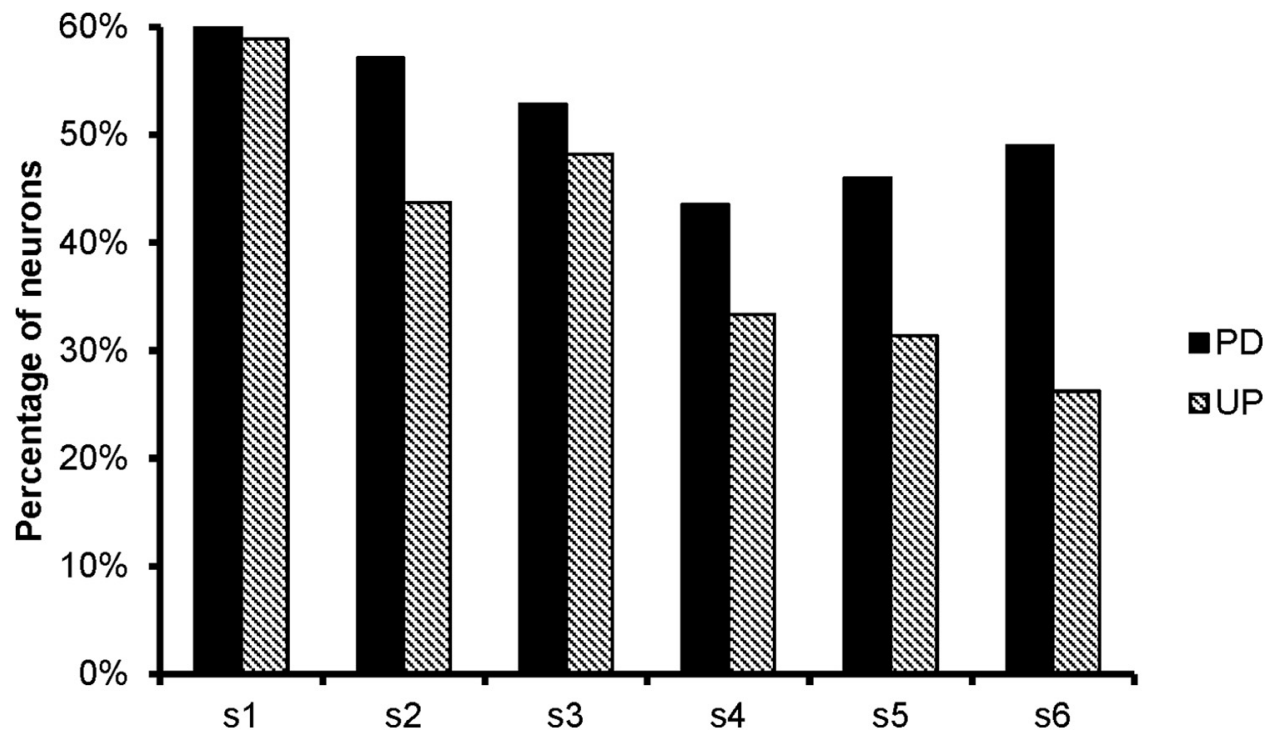

Figure 5. Session by session changes in neuronal responsiveness. The proportion of neurons that were responsive to trial stimuli significantly decreased during both paired and unpaired training.

P21-23

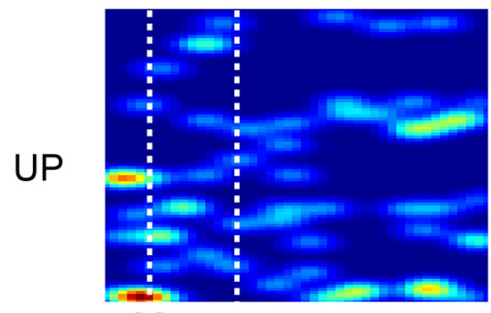

CS

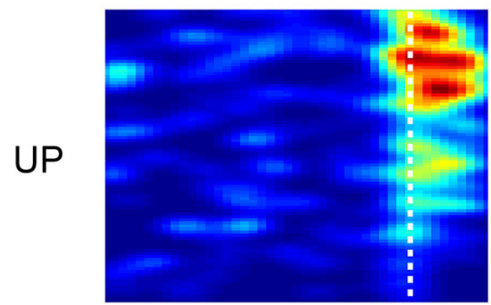

US

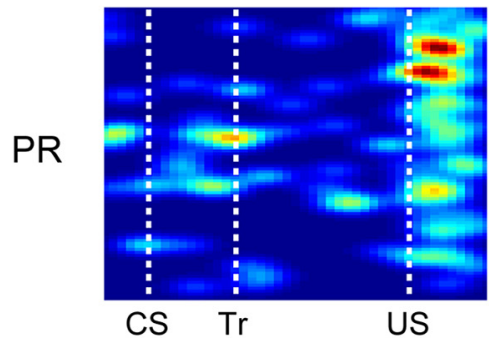

P24-26

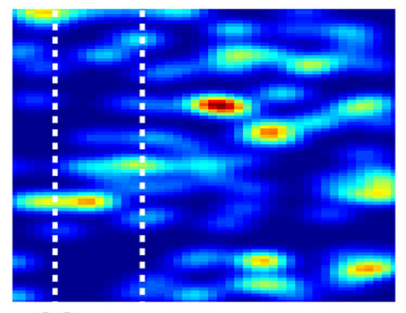

CS

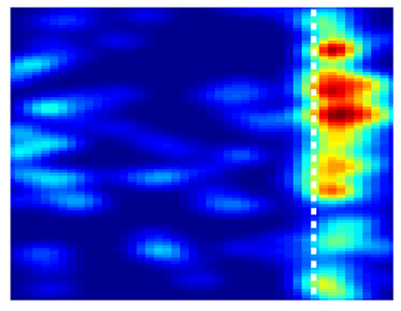

US

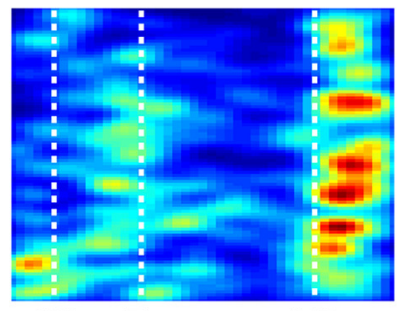

CS $\mathrm{Tr}$
P31-33
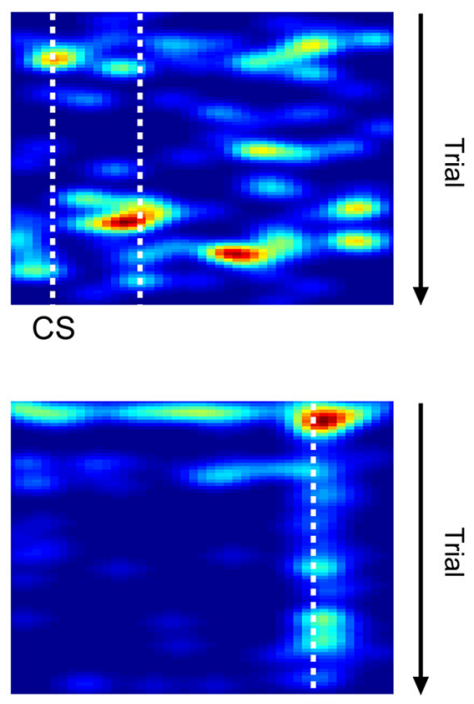

US

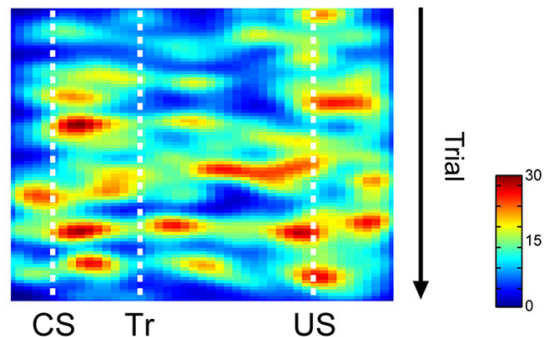

Figure 6. Color map depicting single representative CA1 neuronal firing rate profiles during unpaired and paired training. Firing profiles of six different singleCA1 neurons recorded from rats in the P21-P23, P24-P26, and P31-P33 groups during a single session of either paired or unpaired training. Pups received CS alone and US alone trials during unpaired training. During trace conditioning, the CS and US were separated by a $500 \mathrm{~ms}$ trace (Tr) interval. In each color map, the $x$-axis indicates the CS and US onset time and the $y$-axis represents trial numbers (from top to bottom). Unpaired trials (UP) had low levels of neuronal responding to the CS. However, during paired training (PR), there was an age-related increase in the magnitude of responding during the CS and trace intervals. Firing rates are shown during the baseline (125 ms), CS (250 ms), trace (500 ms), and US (250 ms) periods. Color map scaling ranges from 0 to 30 spikes/s. Dashed lines indicated onset of trial event.

US-responsive $\left[X^{2}(5, N=1310)=24.95, p=0.0001\right]$ neurons decreased significantly as training continued. The proportion of trace-responsive neurons, however, did not change across sessions $\left[X^{2}(5, N=1310)=10.20, p=0.07\right]$.
Magnitude of neuronal responses to trial events

Magnitude of neuronal response during paired training

To determine how the magnitude of the neuronal response changed across age, learning, and stimulus type, activity during 


\section{CR}
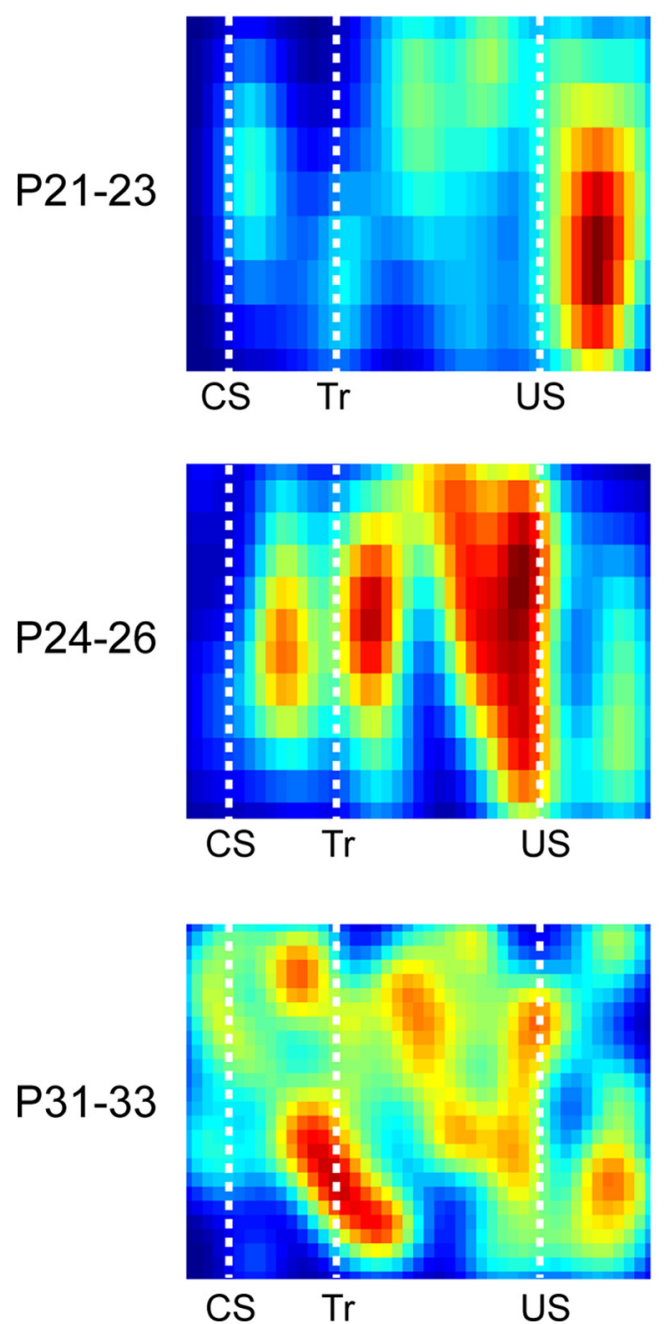

NO-CR
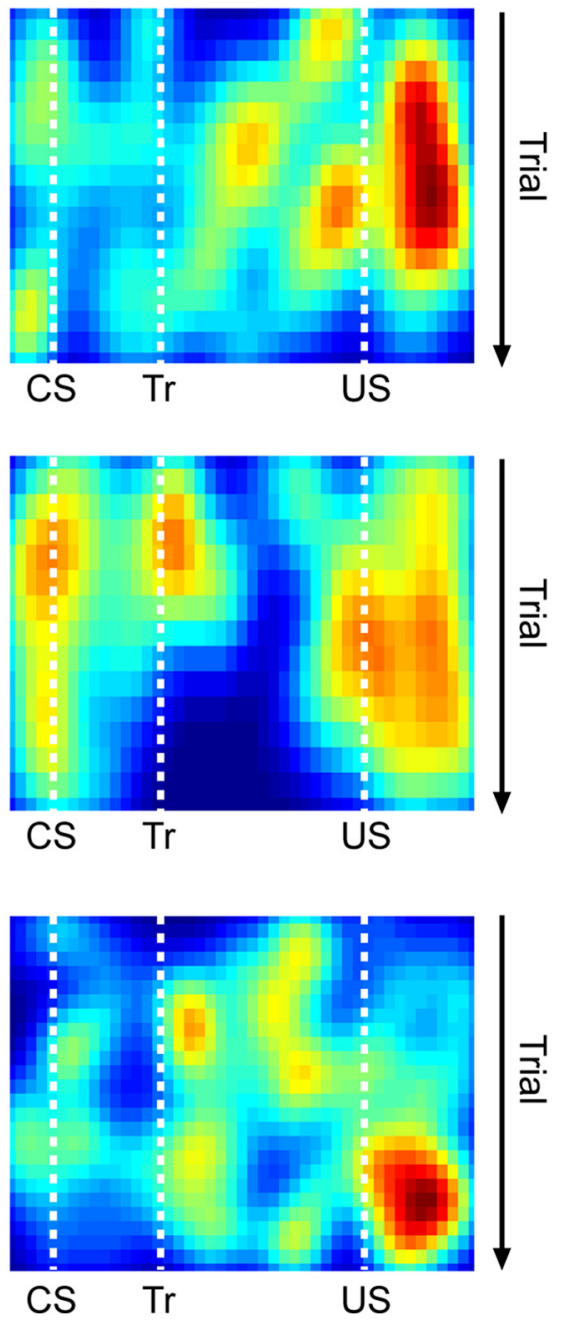

Figure 7. Color map of representative single CA1 pyramidal cell firing rate profiles comparing no-CR and CR trials across age. Firing profiles of three different single CA1 neurons recorded from rats in the P21-P23, P24-P26, and P31-P33 groups during CR and no-CR trials in a single session. On the color map figures, the $x$-axis indicates the event time onset and the $y$-axis indicates time (from top to bottom). Firing rates are shown during the baseline ( $125 \mathrm{~ms})$, CS ( $250 \mathrm{~ms})$, trace $(500 \mathrm{~ms})$, and US ( $250 \mathrm{~ms}$ ) periods. The neurons recorded from the older pups show greater activity during the $C S$ and trace interval during $C R$ trials compared with no-CR trials. These neurons also show a stronger response to the US on no-CR trials. In contrast, the neuron recorded from the youngest pup shows very little change in responding between $C R$ and no-CR trials. Color map scaling is based upon the maximum value of each image. Dashed lines indicated onset of trial event.

trials was normalized to the pre-CS baseline (see "Materials and Methods" section). Normalized neuronal activity of responsive neurons (Figs. 6, 7, 8) was then examined with repeatedmeasures ANOVA to determine which time bins were significantly affected by age and whether the animal showed a CR. Therefore, the magnitude of the response was compared across age groups and learning. Overall, there was a significant age $\times$ $\mathrm{CR} \times$ time bin interaction $\left(F_{(41.87,19196.93)}=1.486, p=0.022\right)$. Tukey post hoc tests controlling for the number of comparisons and the Tukey-Kramer approach to unequal " $n$ " were run on individual bins. These post hoc tests indicated that the oldest two age groups showed greater neuronal activity during the CS and trace periods on CR trials relative to no-CR trials (Fig. 8). Specifically, in the P24-P26 and P31-P33 age groups, there were 30 and 45 (respectively) of 60 total bins that were significantly lower in the no-CR trials compared with the CR trials during the CS and trace periods. In contrast, when examining this averaged activity, all age groups had a decrease in the magnitude of responding to the US during CR trials when compared with no-CR trials, with this effect being most evident in the youngest age group with 13 of 20 bins showing significant decreases (Fig. 8). Learning was therefore associated with an age-related increase in the magnitude of the neuronal response during the CS and trace interval, but a decrease after the US. In addition, there were age-related differences in the magnitude of neuronal responding across groups during CR trials. Specifically, four of 20 bins were significantly lower in the youngest age group than the two older age groups during the CS $(p<0.05)$. During the trace interval, six of 40 bins were significantly lower in the youngest age group compared with the older two age groups and, during the US period, 11 of 20 bins were significantly lower in the youngest age group than the older two age groups $(p<0.05)$.

\section{Magnitude of neuronal response during unpaired training}

The magnitude of the neuronal response was also evaluated during unpaired training (see Fig. 6 for an example of single-unit neuronal activity). Normalized neuronal activity of responsive neurons during either CS- or US-alone unpaired trials was com- 
P21-23

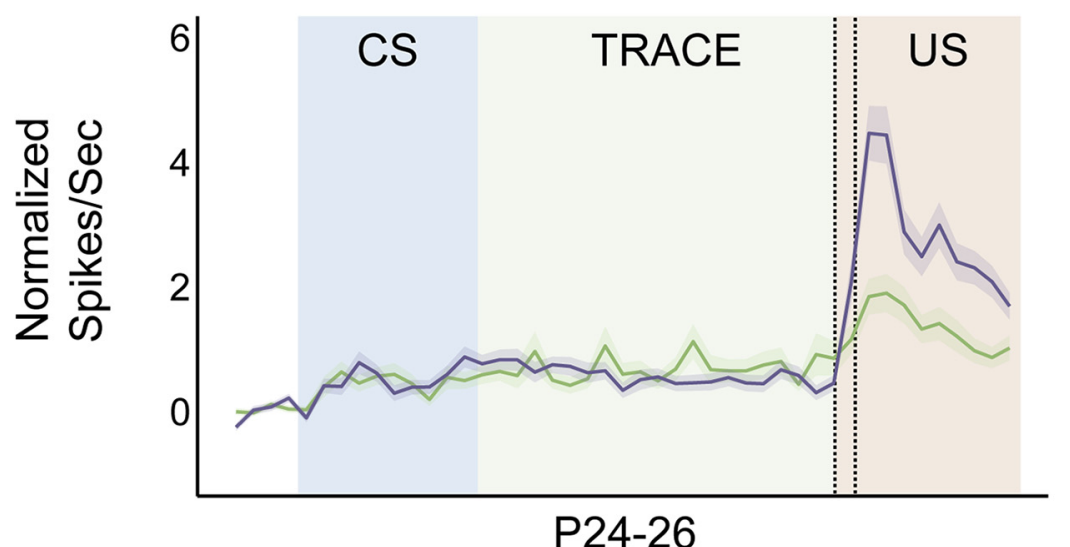

$-\mathrm{CR}$
- No-CR

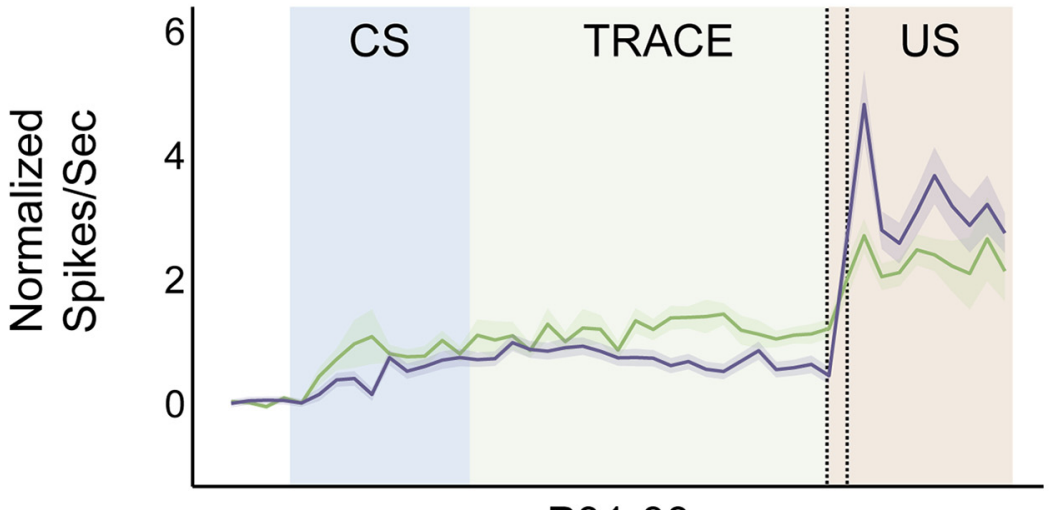

$-\mathrm{CR}$
- No-CR

P31-33

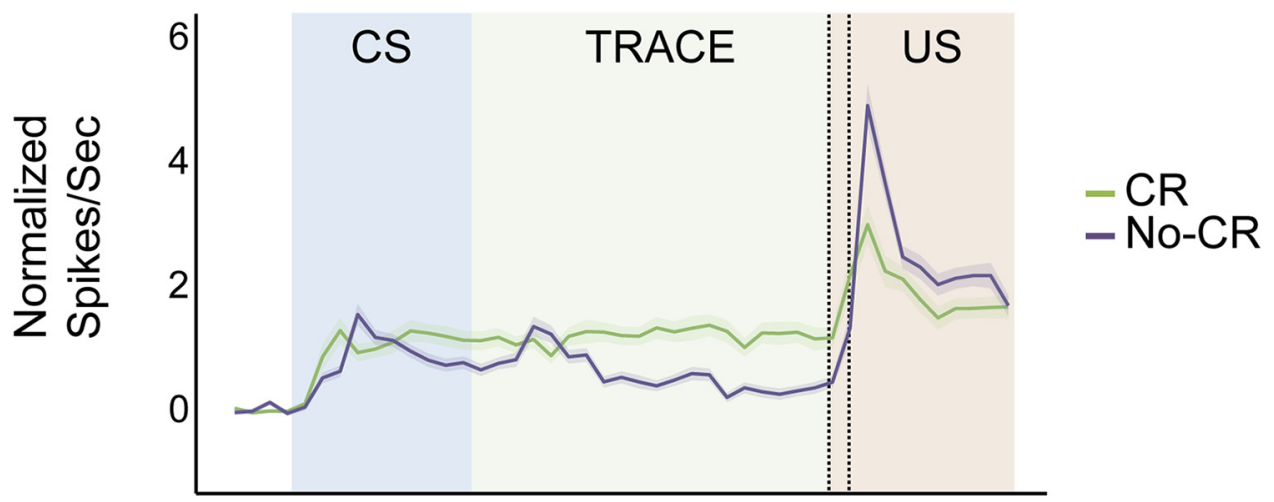

Figure 8. CA1 pyramidal cells show age-and learning-related changes in neuronal activity. To examine population-level changes in activity, the average neuronal firing rates during the baseline, CS $(250 \mathrm{~ms})$, trace $(500 \mathrm{~ms})$, and US ( $250 \mathrm{~ms})$ periods for all responsive neurons were calculated for each age group across all paired sessions. Each graph compares trials with a CR and trials without a CR for a given age group. The shaded areas along the lines indicate the SEM across neurons. Firing rates were normalized to pre-CS baseline activity. Hippocampal neurons in the pups trained on P24-P26 and P31-P33 showed greater activity during the CS and trace interval on CR trials than on no-CR trials, an associative effect not seen on P21-P23. Conversely, across all ages, the presence of a CR was associated with a decrease in the neuronal firing rate in response to the US. This difference was greatest and most prolonged in the youngest age group. These findings suggest that the magnitude of associative activity during the $C S$ and trace interval increased between P21 and P24. Moreover, the magnitude of responsiveness to the US may be inversely related to performing a conditioned response.

pared across age groups. When the magnitude of responding for unpaired CS-responsive neurons was examined, there was no effect of age on the magnitude of the neuronal response. This is in stark contrast to the robust age-related changes in response magnitude to the CS observed during paired training, a finding that suggests that the presence of the associative context is sufficient to produce increased activity during the CS presentation.

When the magnitude of responding for unpaired US responsive neurons was examined, there was a significant effect of age on the magnitude of the neuronal response $\left(F_{(178,18245)}=2.175, p=\right.$
0.0000001). Post hoc tests showed that differences in the magnitude of responding were observed only in the first $150 \mathrm{~ms}$ after the US onset $(p<0.05)$. Specifically, four of 20 bins were significantly higher in the $\mathrm{P} 21-\mathrm{P} 23$ than the $\mathrm{P} 24-\mathrm{P} 26$ group, three of 20 bins were significantly higher in the P21-P23 than the P31-P34 group, and two of 20 bins were higher in the P31-P34 group than the P24-P26 group. However, unlike the differences observed in the magnitude of responding during paired training, no clear overall developmental changes were evident in these differences. 
P21-23

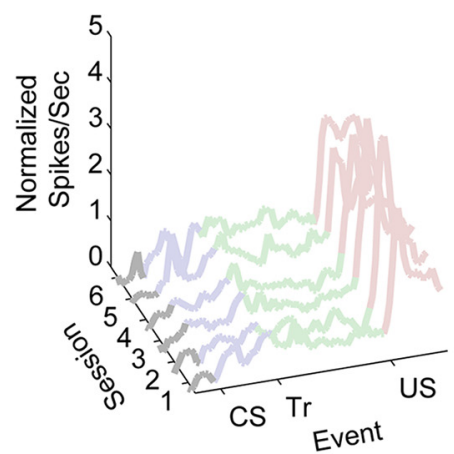

P24-26

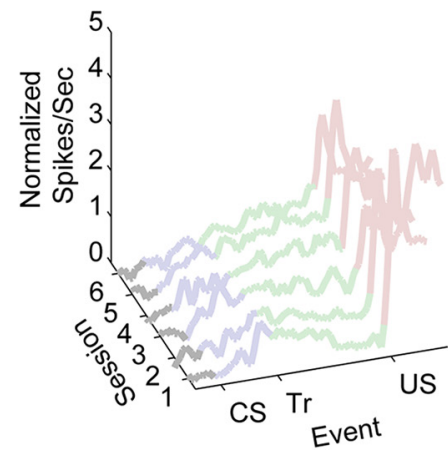

P31-33

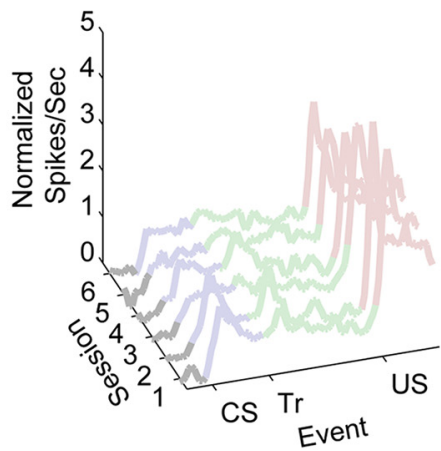

Figure 9. CA1 neuronal firing rate magnitude across sessions and age groups. The average normalized firing rate from responsive CA1 pyramidal cells was compared across session and age group. The $x$-axis shows the event onset time, the $y$-axis indicates normalized spikes/s values, and the $z$-axis represents the session numbers. During trace conditioning, the CS and US were separated by a $500 \mathrm{~ms}$ trace (Tr) interval. There was an age-related increase in firing rate during the $C S$ and trace intervals. Importantly, this developmental change was primarily evident during the first two sessions. See Table 2 for details. Firing rates are shown during the pre-CS baseline (125 ms), CS (250 ms), trace (500 ms), and US (250 ms) periods.

Table 2. Session differences in the magnitude of responding between age groups

\begin{tabular}{clclllll}
\hline & Interval & Session 1 & Session 2 & Session 3 & Session 4 & Session 5 & Session 6 \\
\hline P21-P23 vs & CS & 0 & 0 & 0 & 0 & 1 & 0 \\
P24-P26 & Trace & 0 & 0 & 0 & 3 & 0 & 0 \\
& US & 18 & 7 & 5 & 1 & 5 & 1 \\
P21-P23 vs & CS & 2 & 3 & 0 & 1 & 0 & 0 \\
P31-P33 & Trace & 1 & 3 & 0 & 2 & 0 & 0 \\
& US & 9 & 5 & 5 & 1 & 3 & 2 \\
P24-P26 vs & CS & 7 & 5 & 0 & 1 & 0 & 1 \\
P31-P33 & Trace & 2 & 3 & 0 & 2 & 0 & 0 \\
& US & 13 & 5 & 8 & 5 & 1 & 0 \\
\hline
\end{tabular}

The magnitude of responding was broken down by session and compared across age group (see Fig. 9). The number of bins that differed significantly between age groups for sessions $1-6$ is depicted in columns. The age group and the trial interval (CS, trace, US) during which the significant bins occurred are depicted in rows. The majority of changes that occurred during the $C S$ and trace intervals occurred during the first two sessions. The magnitude of responding during the US did not show any clear age- or session-related patterns.

Changes in the magnitude of neuronal response across session When the magnitude of responding for different age groups was compared across sessions, a repeated-measures ANOVA on responsive cells found an age $\times$ session $\times$ time bin interaction $\left(F_{(219.927,14735.123)}=1.664, p=0.0000001\right.$; Fig. 9$)$. Tukey post hoc tests $(P<0.05)$ indicated that the majority of age-related changes in activity to the CS and trace interval occurred during the first two sessions of training (Fig. 9). Although there were significant group differences in the magnitude of the neuronal response for individual bins during the US period, a clear developmental trend was not apparent. Table 2 depicts the number of significant bins between age groups during the CS, trace, and US intervals. During both sessions 1 and 2, the oldest age group had a significantly increased magnitude of responding during the CS period compared with the younger two age groups. Although there were a few bins that showed increases in magnitude during the trace interval compared with the younger two age groups, this effect was far more noticeable during session 2 .

\section{Discussion}

As seen in previous studies (Ivkovich et al., 2000), rat pups trained in trace eyeblink conditioning did not show robust levels of conditioned responding until nearly the fourth postnatal week. This developmental trajectory is very similar to that seen in studies of spatial learning (Rudy and Paylor, 1988; Green and Stanton, 1989; Freeman and Stanton, 1991). However, just as observed in place cell development (Langston et al., 2010; Wills et al., 2010), the development of neuronal activity preceded the development of the behavior. Even at the youngest age tested here (P21-P23), hippocampal CA1 pyramidal cells showed changes related to associative learning. There was significantly greater responsivity to trial events when presented in the paired context than when presented in the unpaired context. Therefore, even though the youngest rats were not showing overt behavioral signs of learning, they did, at the neuronal level, recognize the difference between associative and nonassociative contexts. However, the pattern of neuronal responsivity in younger rats differed substantially from more mature rats. This difference in CA1 responsiveness may be one of the underlying factors contributing to the developmental change in trace eyeblink conditioning. During paired sessions, neurons of younger rats were more likely to respond to a single trial event, such as the US, whereas neurons of older rats were more likely to respond to a combination of trial events. The CA1 pyramidal cells of younger pups also showed a lower magnitude of responding during conditioning trials. This pattern of responsiveness suggests that the hippocampus of older rats is sufficiently developed to bind the US with other trial events, thus providing the basis for richer associative coding.

CA1 pyramidal cells also showed changes in responsivity across training sessions. Just as seen in adult animals, there was a decrease in responding to both the CS and the US as sessions progressed (McEchron and Disterhoft, 1997). Moreover, these changes were most evident in the oldest age group. These results support the current hypothesis that hippocampal involvement may be most critical early in training (Takehara et al., 2003).

All age groups showed differences in the magnitude of CA1 pyramidal cell responding to the US between learning and nonlearning trials. However, in older animals, learning was associated with an increase in neuronal responsiveness to the CS and trace intervals. This increased responding could be a neuronal representation of the pups attending to CS and trace intervals as salient predictors of the US. Conversely, the increased magnitude of neuronal responding to the US during no-CR trials could indicate that the pup is "surprised" by the arrival of the US (i.e., a prediction error; Rescorla and Wagner, 1972).

A number of developmental changes in both neurogenesis rates and cellular function occur during these ages that might explain the developmental changes in CA1 activity. There is an age-related increase in the strength of CA3-CA1 synapses due to an increase in the probability of transmitter release (Dumas and Foster, 1995), which in turn could be a result of age-related changes in adenylyl cyclase expression (Matsuoka et al., 1997). 
Moreover, there is an overall increase in synaptic connectivity across development as indicated by an age-related increase in synaptic number and density (Harris et al., 1992; Hsia et al., 1998). There is also some evidence that there is a postsynaptic decrease in LTP induction threshold, thus contributing to greater levels of depolarization (Dumas, 2012). These and other changes in synaptic connectivity result in overall changes in synaptic plasticity. In addition to synaptic plasticity mechanisms, the rate of neurogenesis in the dentate gyrus could play a role in the development of hippocampal forms of learning (Akers et al., 2014). High rates of neurogenesis, as seen early in the postnatal development of altricial species such as rats, are related to weaker memory and thus blocking dentate gyrus neurogenesis in young animals results in better retention (Akers et al., 2014). Developmental changes in dentate gyrus function related to changes in neurogenesis might have downstream effects on CA1 function that influence CA1 responses during associative learning. Therefore, developmental changes in synaptic function and neurogenesis rates in the dentate gyrus may be reflected in the development of learning-related neuronal activity in CA1 pyramidal cells described here.

Developmental changes in hippocampal associative coding identified in the present study provide a more mechanistic understanding of the development of learning and memory relative to previous studies that relied on inferred mechanisms from developmental changes in learning or deficits produced by lesions. Previous studies of hippocampal function found that some of the quantitative features of place fields developed as a nearly linear function of postnatal age (Langston et al., 2010; Wills et al., 2010). Our findings suggest, however, that developmental changes in hippocampal associative coding are more abrupt developmentally, with a substantial transition in between P21 and P24. The developmental increases in the strength and complexity of hippocampal coding may underlie the development of other hippocampus-dependent processes such as episodic memory, which requires integration of object, spatial, and temporal information.

\section{References}

Akers KG, Martinez-Canabal A, Restivo L, Yiu AP, De Cristofaro A, Hsiang HL, Wheeler AL, Guskjolen A, Niibori Y, Shoji H, Ohira K, Richards BA, Miyakawa T, Josselyn SA, Frankland PW (2014) Hippocampal neurogenesis regulates forgetting during adulthood and infancy. Science 344: 598-602. CrossRef Medline

Berger TW, Alger B, Thompson RF (1976) Neuronal substrate of classical conditioning in the hippocampus. Science 192:483-485. CrossRef Medline

Clark RE, Manns JR, Squire LR (2002) Classical conditioning, awareness, and brain systems. Trends Cogn Sci 6:524-531. CrossRef Medline

Dumas TC (2012) Postnatal alterations in induction threshold and expression magnitude of long-term potentiation and long-term depression at hippocampal synapses. Hippocampus 22:188-199. CrossRef Medline

Dumas TC, Foster TC (1995) Developmental increase in ca3-cal presynaptic function in the hippocampal slice. J Neurophysiol 73:1821-1828. Medline

Freeman JH Jr, Stanton ME (1991) Fimbria-fornix transections disrupt the ontogeny of delayed alternation but not position discrimination in the rat. Behav Neurosci 105:386-395. CrossRef Medline

Gormezano I, Kehoe EJ, Marshall BS (1983) Twenty years of classical conditioning with the rabbit. Progress in Psychobiology and Physiological Psychology 10:197-275.

Green RJ, Stanton ME (1989) Differential ontogeny of working memory and reference memory in the rat. Behav Neurosci 103:98-105. CrossRef Medline

Green JT, Arenos JD (2007) Hippocampal and cerebellar single-unit activity during delay and trace eyeblink conditioning in the rat. Neurobiol Learn Mem 87:269-284. Medline

Harris KM, Jensen FE, Tsao B (1992) Three-dimensional structure of dendritic spines and synapses in rat hippocampus (cal) at postnatal day 15 and adult ages: Implications for the maturation of synaptic physiology and long-term potentiation. J Neurosci 12:2685-2705. Medline

Hsia AY, Malenka RC, Nicoll RA (1998) Development of excitatory circuitry in the hippocampus. J Neurophysiol 79:2013-2024. Medline

Ivkovich D, Paczkowski CM, Stanton ME (2000) Ontogeny of delay versus trace eyeblink conditioning in the rat. Dev Psychobiol 36:148-160. CrossRef Medline

Ivkovich D, Stanton ME (2001) Effects of early hippocampal lesions on trace, delay, and long-delay eyeblink conditioning in developing rats. Neurobiol Learn Mem 76:426-446. CrossRef Medline

Kadir SN, Goodman DF, Harris KD (2014) High-dimensional cluster analysis with the masked em algorithm. Neural Comput 26:2379-2394. CrossRef Medline

Langston RF, Ainge JA, Couey JJ, Canto CB, Bjerknes TL, Witter MP, Moser EI, Moser MB (2010) Development of the spatial representation system in the rat. Science 328:1576-1580. CrossRef Medline

Matsuoka I, Suzuki Y, Defer N, Nakanishi H, Hanoune J (1997) Differential expression of type $\mathrm{i}, \mathrm{ii}$, and $\mathrm{v}$ adenylyl cyclase gene in the postnatal developing rat brain. J Neurochem 68:498-506. Medline

McEchron MD, Disterhoft JF (1997) Sequence of single neuron changes in cal hippocampus of rabbits during acquisition of trace eyeblink conditioned responses. J Neurophysiol 78:1030-1044. Medline

Moyer JR Jr, Deyo RA, Disterhoft JF (1990) Hippocampectomy disrupts trace eye-blink conditioning in rabbits. Behav Neurosci 104:243-252. CrossRef Medline

$\mathrm{Ng} \mathrm{KH}$, Freeman JH (2012) Developmental changes in medial auditory thalamic contributions to associative motor learning. J Neurosci 32:68416850. CrossRef Medline

Redish AD, Battaglia F, Cowen S, Jackson JC, Lipa P, Schmitzer-Torbert NC (2010) Mclust. Available from: http://redishlab.neuroscience.umn.edu/ MClust/MClust.html.

Rescorla RA, Wagner AR (1972) A theory of Pavlovian conditioning: variations in the effectiveness of reinforcement and nonreinforcement. Classical Conditioning II: Current Research and Theory 2:64-99.

Rudy J, Paylor R (1988) Reducing the temporal demands of the morris place-learning task fails to ameliorate the place-learning impairment of preweanling rats. Psychobiology 16:152-156.

Smotherman WP (1982) Odor aversion learning by the rat fetus. Physiology and Behavior 29:769-771. CrossRef Medline

Solomon PR, Vander Schaaf ER, Thompson RF, Weisz DJ (1986) Hippocampus and trace conditioning of the rabbit's classically conditioned nictitating membrane response. Behav Neurosci 100:729-744. CrossRef Medline

Stanton ME (2000) Multiple memory systems, development and conditioning. Behav Brain Res 110:25-37. CrossRef Medline

Stanton ME, Freeman JH Jr, Skelton RW (1992) Eyeblink conditioning in the developing rat. Behav Neurosci 106:657-665. CrossRef Medline

Stanton ME, Ivkovich Claflin D, Herbert J (2009) Ontogeny of multiple memory systems eyeblink conditioning in rodents and humans. In: Blumberg MS, Freeman JH, Robinson SR (eds). Oxford handbook of developmental behavioral neuroscience, pp 501-526. New York: Oxford UP.

Takehara K, Kawahara S, Kirino Y (2003) Time-dependent reorganization of the brain components underlying memory retention in trace eyeblink conditioning. J Neurosci 23:9897-9905. Medline

Weible AP, O’Reilly JA, Weiss C, Disterhoft JF (2006) Comparisons of dorsal and ventral hippocampus cornu ammonis region 1 pyramidal neuron activity during trace eye-blink conditioning in the rabbit. Neuroscience 141:1123-1137. CrossRef Medline

Wills TJ, Cacucci F, Burgess N, O'Keefe J (2010) Development of the hippocampal cognitive map in preweanling rats. Science 328:1573-1576. CrossRef Medline 